\title{
Fast and efficient Maximum Power Point Tracking controller for photovoltaic modules
}

\author{
Khalid Chennoufi ${ }^{*}$, Mohammed Ferfra
}

Department of Electrical Engineering, Mohammadia School of Engineers, Mohammed V University in Rabat, Rabat, PB765, Morocco

\begin{tabular}{l} 
A R T I C L E I N F O \\
\hline Article history: \\
Received: 31 July, 2020 \\
Accepted: 06 November, 2020 \\
Online: 24 November, 2020 \\
\hline
\end{tabular}

Keywords:

Artificial Neural Network

Backstepping

$M P P T$

Double diode model

SEPIC

\begin{abstract}
A B S T R A C T
This paper presents an efficient Maximum Power Point Tracking (MPPT) controller for photovoltaic modules. The MPPT technique consists of a combination between backstepping controller and artificial neural network (ANN). The (ANN) has been employed to generate the optimum voltage, which corresponds to the maximum power voltage delivered by photovoltaic modules, while the backstepping controller is developed to track the generated voltage, by computing the duty cycle of the Single Ended Primary Inductor Converter (SEPIC). The control of the boost converter is based on Lyapunov stability analysis, and an integral action is added to increase system robustness. In order to prove the accuracy of the developed control a comparison between the proposed method and sliding mode was carried out. In addition the stability was evaluated under sudden variation of environmental conditions. The simulation was carried out in MATLAB software, the results shows that the proposed controller tracks the reference voltage within $25 \mathrm{~ms}$, in addition the systems reacts to sudden environments change with no oscillations, which demonstrate the robustness of the proposed method.
\end{abstract}

\section{Introduction}

In recent years, the demand of electrical energy increases, which reduces the reserves of the conventional resources and increases the global warming, therefore the use of renewable energies is the only way to reduce the dependence on fossil fuels and ensure the energy security. In fact, photovoltaic energy is the most popular renewable energy source, however, the output power relies on weather conditions and the load. This led the researchers to present various algorithms that make photovoltaic modules operates in the maximum power point. Thus a various Maximum Power Point Tracking algorithms with different degrees of complexity and precision have been proposed in the literature [1-3]. The perturb and the observe, and incremental conductance [4], methods are often used due to their simplicity and ease of implementation, however their main drawback is the fluctuations around the point of maximum power.

Thus to overcome the oscillations issues and increase the performance of the tracking a combination between direct control methods and the nonlinear commands has been employed by the researchers.

${ }^{*}$ Corresponding Author: Khalid Chennoufi, Tel: +212 6680115 90, khalidchennoufi@research.emi.ac.ma

www.astesi.com

https://dx.doi.org/10.25046/aj050674
In [5], Authors propose a maximum power point tracking controller for hybrid Photovoltaic - Wind energy system. The controller is developed by the combination of perturb \& observe and Sliding Mode. P\&O loop is used for the computation of the reference voltage, while Sliding Mode is designed to track this voltage by generating the control signal. The proposed method exhibits good convergence speed, but the main disadvantage is the oscillations around maximum power point.

In [6], Authors present a control of a single-phase Photovoltaic inverter using backstepping algorithm which track the desired voltage generated by Perturb and Observe method and adjust the duty cycle in order to operate in maximum power point. The error between the output and reference voltage was eliminated quickly, but some fluctuations have been observed in the desired operating point.

In [7], Authors propose a maximum power point tracking controller for Photovoltaic system. The controller is developed by the combination of Sliding Mode and Artificial Neural Network (ANN). The ANN is employed to generate the reference voltage, while Sliding Mode is designed to track this voltage by generating the control signal. The proposed method presents good 
performance; however, some oscillations is noticed around maximum power point.

In order to overcome fluctuation issues around maximum power point, this paper proposes a hybrid method, which consists of a backstepping controller combined to the Artificial Neural Network (ANN). The ANN is employed to generate the reference voltage, while backstepping controller is designed to adjust the duty cycle of the converter in order to track the desired voltage, which corresponds to the voltage of the Maximum Power Point, (Fig1).

In contrast of previous methods which adopt single diode model, the photovoltaic modelling was carried out using double diode model, as the modelling using single diode degrade at low irradiance. In addition the present work doesn't rely on any simplification which can compromise the accuracy of the controller modelling, furthermore the SEPIC converter was employed since it offer more advantages instead of the traditional converter.

The present paper is organized as follows. In Section 2, the modelling of the PV system is presented. The Section 3, presents the design of the proposed controller. The simulations and discussions are illustrated in Section 4.

\section{Modelling of PV system}

The Photovoltaic system proposed in this paper consists of a photovoltaic module connected to a resistive load through a Single ended primary converter as shown in Figure 1.

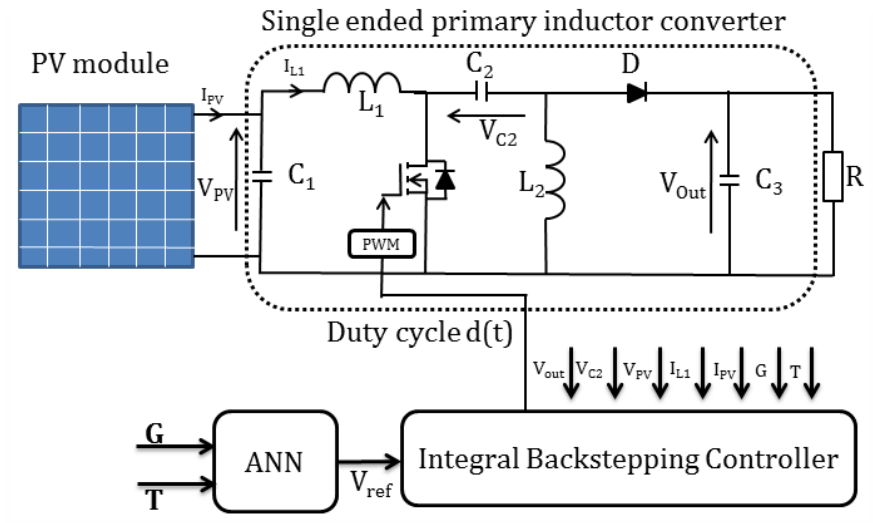

Figure 1: Illustration of the proposed Photovoltaic system.

Where $\mathrm{V}_{\text {out }}, \mathrm{V}_{\mathrm{c} 2}, \mathrm{~V}_{\mathrm{PV}}$ are the output voltage, the voltage across the capacitor $\mathrm{C}_{2}$, and the photovoltaic voltage respectively, $\mathrm{I}_{\mathrm{pv}}$ and $\mathrm{I}_{\mathrm{L} 1}$ are the photovoltaic and inductor 1 currents, While $\mathrm{G}$ and $\mathrm{T}$ are respectively the irradiation and the Temperature.

The datasheet parameters of the polycrystalline photovoltaic module KD 245 GH are presented in Table 1.
Table 1: PV module datasheet

\begin{tabular}{ll}
\hline Parameter & Value \\
\hline Short-circuit current $\left(\mathrm{I}_{\mathrm{sc}}\right)$ & $8.91(\mathrm{~A})$ \\
Open circuit voltage $\left(\mathrm{V}_{\mathrm{oc}}\right)$ & $36.9(\mathrm{~V})$ \\
Maximum current $\left(\mathrm{I}_{\mathrm{m}}\right)$ & $8.23(\mathrm{~A})$ \\
Maximum voltage $\left(\mathrm{V}_{\mathrm{m}}\right)$ & $29.8(\mathrm{~V})$ \\
Number of cells in series $\left(\mathrm{N}_{\mathrm{s}}\right)$ & 60 \\
Temperature coefficient of current $\left(\mathrm{k}_{\mathrm{i}}\right)$ & $5.35 \times 10^{-3}$ \\
& $(\mathrm{~A} / \mathrm{K})$ \\
Temperature coefficient of voltage & $-0.133(\mathrm{~V} / \mathrm{K})$ \\
$\left(\mathrm{K}_{\mathrm{V}}\right)$ & \\
\hline
\end{tabular}

\subsection{Modelling of the SEPIC converter}

The SEPIC is an acronym of (single ended primary inductor converter), which is a DC-DC converter capable to operate as boost or buck mode [8], that offer the possibility to raise or decrease the voltage at the output [9]. In addition the SEPIC converter makes the PV system operate at its maximum power point with 'weak current ripples [10]. Furthermore it can work on any operating point by changing the duty cycle [11]. The converter is modelled mathematically based on these states [12] as shown in figure 2 .
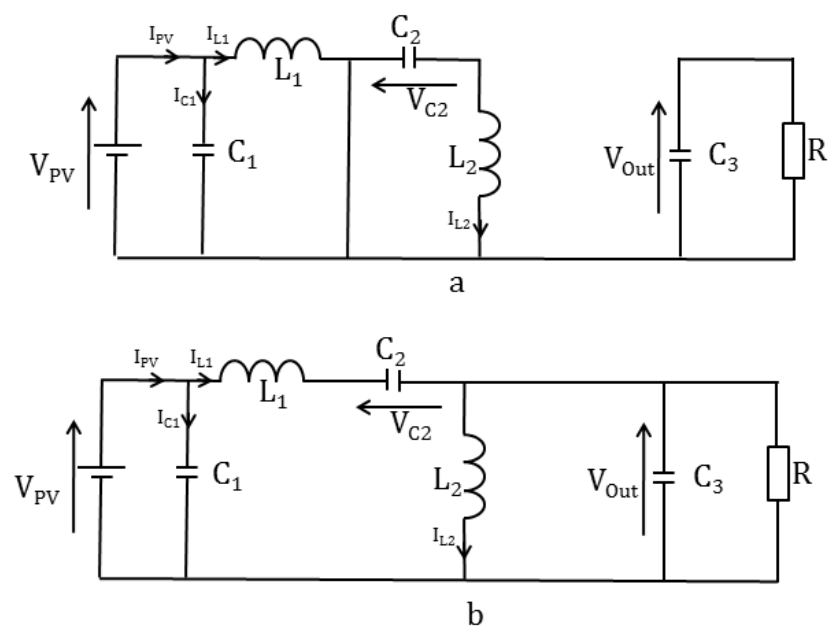

Figure 2: SEPIC converter circuit, (a) Equivalent circuit switch is ON (b) switch is $\mathrm{OFF}$

When the commutator is on $(u=1)$ as shown in figure 2-a. The capacitor $\mathrm{C}_{3}$ supplies energy to the load and the energy stored in the inductances increases, the inductor $\mathrm{L} 1$ is alimented from the input while the inductor $\mathrm{L}_{2}$ is feeded from the capacitor $\mathrm{C}_{2}$. The representation of state space can be described as

$$
\begin{aligned}
& \frac{\mathrm{dI}_{\mathrm{L} 1}}{\mathrm{dt}}=\frac{\mathrm{V}_{\mathrm{PV}}}{\mathrm{L}_{1}} \\
& \frac{\mathrm{dI}_{\mathrm{L} 2}}{\mathrm{dt}}=\frac{-\mathrm{V}_{\mathrm{C} 2}}{\mathrm{~L}_{2}} \\
& \frac{\mathrm{dV}_{\mathrm{c} 2}}{\mathrm{dt}}=\frac{\mathrm{I}_{\mathrm{L} 2}}{\mathrm{C}_{2}}
\end{aligned}
$$


When the commutator is off $(\mathrm{u}=0)$ as shown in figure 2-b. The two inductors are discharged and the energy stored in the capacitors increases. The representation of state space can be written as:

$$
\begin{aligned}
\frac{\mathrm{dI}_{\mathrm{L} 1}}{\mathrm{dt}} & =\frac{\mathrm{V}_{\mathrm{PV}}-\mathrm{V}_{\mathrm{C} 2}-\mathrm{V}_{\text {out }}}{\mathrm{L}_{1}} \\
\frac{\mathrm{dI}_{\mathrm{L} 2}}{\mathrm{dt}} & =\frac{\mathrm{V}_{\text {out }}}{\mathrm{L}_{2}} \\
\frac{\mathrm{dV} \mathrm{V}_{\mathrm{C} 2}}{\mathrm{dt}} & =\frac{\mathrm{I}_{\mathrm{L} 1}}{\mathrm{C}_{2}}
\end{aligned}
$$

The combination between the two state spaces can be expressed as:

$$
\begin{aligned}
& \frac{\mathrm{dI}_{\mathrm{L} 1}}{\mathrm{dt}}=\frac{(\mathrm{u}-1) \mathrm{V}_{\mathrm{C} 2}}{\mathrm{~L}_{1}}+\frac{(\mathrm{u}-1) \mathrm{V}_{\text {out }}}{\mathrm{L}_{1}}+\frac{\mathrm{V}_{\mathrm{PV}}}{\mathrm{L}_{1}} \\
& \frac{\mathrm{dV}_{\mathrm{C} 2}}{\mathrm{dt}}=\frac{(1-\mathrm{u}) \mathrm{I}_{\mathrm{L} 1}}{\mathrm{C}_{2}}+\frac{\mathrm{uI}_{\mathrm{L} 2}}{\mathrm{C}_{2}} \\
& \frac{\mathrm{dI}_{\mathrm{L} 2}}{\mathrm{dt}}=-\frac{\mathrm{dV}_{\mathrm{C} 2}}{\mathrm{~L}_{2}}+\frac{(1-\mathrm{u}) \mathrm{V}_{\text {out }}}{\mathrm{L}_{2}} \\
& \frac{\mathrm{dV}}{\mathrm{dt}}=\frac{(1-\mathrm{u}) \mathrm{I}_{\mathrm{L} 1}}{\mathrm{C}_{3}}+\frac{(\mathrm{u}-1) \mathrm{I}_{\mathrm{L} 2}}{\mathrm{C}_{3}}-\frac{\mathrm{V}_{\text {out }}}{\mathrm{RC}_{3}}
\end{aligned}
$$

where $\mathrm{u}=(0$ or 1$)$

\subsection{Modelling of the Photovoltaic module}

In this work the modelling of a solar module is developed based on double diode model which is illustrated in figure 3 , where the first diode describes the saturation currents due to diffusion mechanism, while the second diode describes the current due to recombination in the depletion zone.

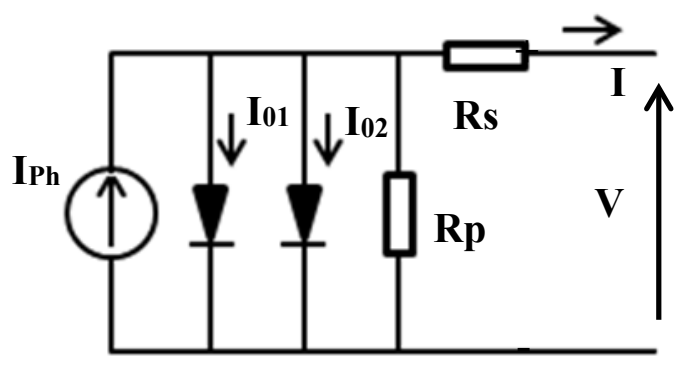

Figure 3: Illustration of the double diode model.

The output current of a solar cell is represented by:

$I=I_{p h}-I_{01}\left(\exp \left(\frac{V+R_{S} I}{a_{1} V_{T}}\right)-1\right)-I_{02}\left(\exp \left(\frac{V+R_{S} I}{a_{2} V_{T}}\right)-1\right)-$

$\frac{V+R_{S} I}{R_{p}}$

The unknown parameters such as: $\mathrm{a}_{1}, \mathrm{a}_{2}, \mathrm{I}_{01}, \mathrm{I}_{02}, \mathrm{I}_{\mathrm{ph}}, \mathrm{R}_{\mathrm{s}}$ and $\mathrm{R}_{\mathrm{p}}$. are extracted using a combination between the equation of three main operating points which are, the open circuit voltage, the short circuit current and the maximum power point. The objective is to find the equations of $\mathrm{I}_{01}, \mathrm{I}_{02}, \mathrm{R}_{\mathrm{p}}$ and $\mathrm{I}_{\mathrm{ph}}$ which depend only of $\mathrm{Rs}$, a1 and $\mathrm{a} 2$. The value of series resistance (Rs) and ideality factors $\left(\mathrm{a}_{1}, \mathrm{a}_{2}\right)$ are obtained using a fast iteration by adjusting simulated and datasheet powers [13]. The extracted parameters are illustrated in Table 2.

The extracted parameters are integrated in a MATLAB algorithm to plot V-I and V-P curves as shown in Figs. 4, the simulation allow to predict the behaviour of the photovoltaic modules in different meteorological condition, thus when the temperature increases the open circuit voltage decrease while the short circuit current increase slightly which result a loss of generated power. On the other hand, when the solar irradiance increases both short circuit current and the open circuit voltage increase which raise the generated power.

Table 2: Extracted Parameters of KD 245GH module

\begin{tabular}{ll}
\hline Parameter & Value \\
\hline $\mathrm{a}_{1}$ & 1.005879 \\
$\mathrm{a}_{2}$ & 1.994120 \\
$\mathrm{I}_{\mathrm{ph}}(\mathrm{A})$ & 8.931164 \\
$\mathrm{I}_{01}(\mathrm{~A})$ & $3.906668 \times 10^{-10}$ \\
$\mathrm{I}_{02}(\mathrm{~A})$ & $1.094485 \times 10^{-06}$ \\
$\mathrm{R}_{\mathrm{s}}(\Omega)$ & 0.286199 \\
$\mathrm{R}_{\mathrm{p}}(\Omega)$ & 120.495147 \\
\hline
\end{tabular}
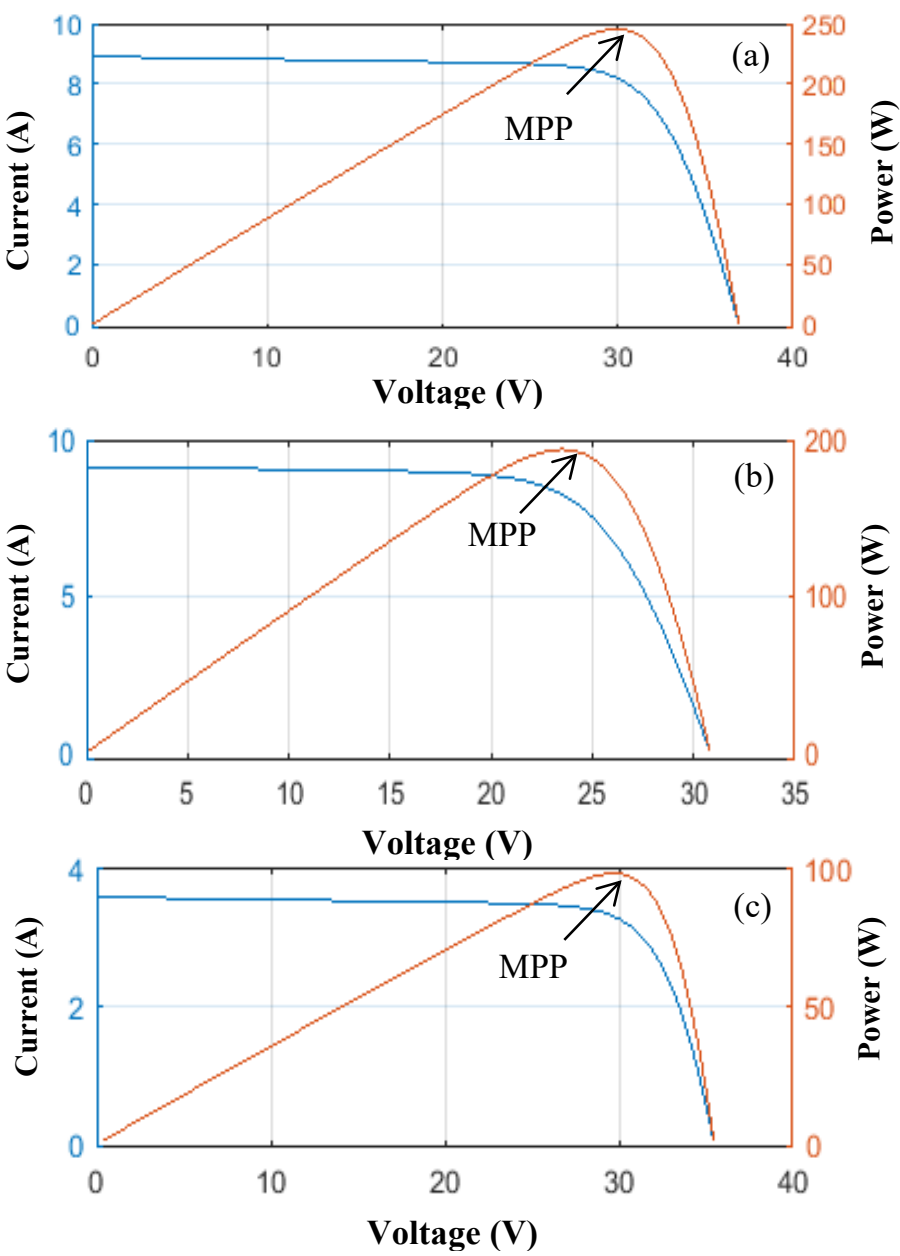

Figure 4: Generated current and power at $25^{\circ} \mathrm{C}-1000 \mathrm{~W} / \mathrm{m}^{2}$ (a), $75^{\circ} \mathrm{C}-1000$ $\mathrm{W} / \mathrm{m}^{2}(\mathrm{~b})$ and $25^{\circ} \mathrm{C}-400 \mathrm{~W} / \mathrm{m}^{2}$ (c) 


\section{Proposed controller:}

Figure 1 presents the schematic drawing of the proposed controller, it consists of a combination between Artificial Neural Network and backstepping controller. The ANN loop generates a voltage reference for every solar irradiation and temperature, which correspond to the maximum power point voltage, while the backstepping controller tracks the generated reference by adjusting the duty cycle.

\subsection{Artificial Neural Network}

Artificial neural network is a computational processing model based on artificial intelligence that is meant to simulate the functioning of a human brain, which consists of processing units interconnected by nodes [14]. The ANN architecture consists of three layers as shown in Figure 5, The input layer receives various forms and structures of information based on an internal weighting system, the hidden layer is where artificial neurons get an ensemble of weighted inputs and generates an output via an activation function, while and the output layer receives data from hidden layer and gives the results of the ANN $[15,16]$.

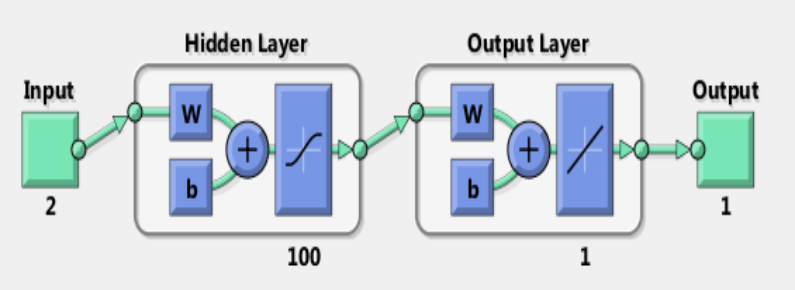

Figure 5: Proposed Neural network hierarchy

In this work the input layer was designed with two neurons, irradiation and the temperature, a database of 158 cases was created by increasing the irradiance by a step of $5 \mathrm{~K}$ from $278 \mathrm{~K}$ to $333 \mathrm{~K}$ and changing the irradiance for each temperature from 200 to $1050 \mathrm{~W} / \mathrm{m}^{2}$. The hidden layer was created with 100 neurons as shown in Figure 5. The output layer has only one neuron which corresponds to the voltage at maximum power of the 158 pair irradiance temperature.

\subsection{Integral backstepping}

The backstepping controller is designed to track the reference voltage generated by the artificial neural network by adjusting the duty cycle of the converter. The control law is generated based on Lyapunov stability analysis. The design of the controller is as follows:

The tracking error is defined as the difference between photovoltaic and reference voltages:

$\mathrm{e}_{1}=\mathrm{Vpv}-$ Vref

An integral action is added in order to improve the tracking precision as follow:

$\mathrm{e}=\mathrm{e}_{1}+\lambda \mathrm{e}_{\text {Int }}$
The tracking error becomes:

$\mathrm{e}=\mathrm{Vpv}-$ Vref $+\lambda \int(\mathrm{Vpv}-$ Vref $) \mathrm{dt}$

Where $\lambda$ is a positive constant

The modified Lyapunov function can be written as:

$V_{1}=\frac{1}{2} e_{1}^{2}+\frac{\lambda}{2} e_{\text {Int }}^{2}$

The derivative of the (15) with respect to time is:

$\dot{\mathrm{V}}_{1}=\mathrm{e}_{1}\left[\left(\dot{\mathrm{V}}_{\mathrm{pv}}-\dot{\mathrm{V}}_{\mathrm{ref}}\right)+\lambda \int(\mathrm{Vpv}-\mathrm{Vref}) \mathrm{dt}\right]$

To guarantee the asymptotic stability, the Lyapunov function has to be negative definite derivative:

$\dot{\mathrm{V}}_{1}=-K_{1} e_{1}^{2}$

where $K_{1}$ is a positive constant

The following equation is obtained:

$\left[\left(\dot{\mathrm{V}}_{\mathrm{pv}}-\dot{\mathrm{V}}_{\mathrm{ref}}\right)+\lambda \int(\mathrm{Vpv}-\mathrm{Vref}) \mathrm{dt}\right]=-\mathrm{K}_{1} \mathrm{e}_{1}$

The photovoltaic current is given by:

$\mathrm{I}_{\mathrm{PV}}=\mathrm{I}_{\mathrm{C} 1}+\mathrm{I}_{\mathrm{L} 1}$

The derivative of photovoltaic tension can be written as:

$\dot{\mathrm{V}}_{\mathrm{pv}}=\frac{\mathrm{I}_{\mathrm{PV}}-\mathrm{I}_{\mathrm{L} 1}}{\mathrm{C}_{1}}$

The desired value of inductor current would be:

$\mathrm{I}_{\mathrm{d}}=\mathrm{I}_{\mathrm{PV}}+\mathrm{C}_{1}\left[\left(\mathrm{~K}_{1} \mathrm{e}_{1}-\dot{\mathrm{V}}_{\mathrm{ref}}\right)+\lambda \int(\mathrm{Vpv}-\mathrm{Vref}) \mathrm{dt}\right]$

where $\left(\mathrm{I}_{\mathrm{d}}=\mathrm{I}_{\mathrm{L} 1}\right)$

The second error represents the difference between the inductor and the desired current:

$\mathrm{e}_{2}=\mathrm{I}_{\mathrm{L} 1}-\mathrm{I}_{\mathrm{d}}$

The derivative of Lyapunov function with respect to the time can be expressed as

$\dot{\mathrm{V}}_{1}=\mathrm{e}_{1}\left[\left(\frac{\mathrm{I}_{\mathrm{PV}}-\left(\mathrm{e}_{2}+\mathrm{I}_{\mathrm{d}}\right)}{\mathrm{C}_{1}}-\dot{\mathrm{V}}_{\mathrm{ref}}\right)+\lambda \int(\mathrm{Vpv}-\mathrm{Vref}) \mathrm{dt}\right]$

By using equation (18) and (20) the above equation can be written as

$\dot{\mathrm{V}}_{1}=-\mathrm{k}_{1} \mathrm{e}_{1}^{2}-\frac{\mathrm{e}_{1} \mathrm{e}_{2}}{\mathrm{C}_{1}}$

The time derivative of (22), using equation (9) can be written as:

$\dot{\mathrm{e}}_{2}=\frac{1}{\mathrm{~L}_{1}} \mathrm{~V}_{\mathrm{pv}}-\frac{1}{\mathrm{~L}_{1}}(1-\mathrm{u})\left(\mathrm{V}_{\mathrm{out}}+\mathrm{V}_{\mathrm{c} 2}\right)-\dot{\mathrm{I}}_{\mathrm{d}}$

Where:

$\dot{\mathrm{I}}_{\mathrm{d}}=\dot{\mathrm{I}}_{\mathrm{PV}}+\mathrm{C}_{1}\left[\left(\mathrm{~K}_{1} \mathrm{e}_{1}-\ddot{\mathrm{V}}_{\mathrm{ref}}\right)+\lambda(\mathrm{Vpv}-\right.$ Vref $\left.)\right]$ 
The derivative of photovoltaic current with respect to the time can be expressed as:

$\dot{\mathrm{I}}_{\mathrm{PV}}=\frac{\mathrm{dI}_{\mathrm{PV}}}{\mathrm{dV} \mathrm{V}_{\mathrm{PV}}} \frac{\mathrm{dV}_{\mathrm{PV}}}{\mathrm{dt}}$

By differentiating the equation (11) with respect to the voltage the derivative of photovoltaic current is obtained:

$$
\begin{gathered}
\dot{\mathrm{I}}_{\mathrm{PV}}=\left[-\frac{\mathrm{I}_{01} \exp \left(\frac{\mathrm{V}+\mathrm{R}_{\mathrm{S}} \mathrm{I}_{\mathrm{PV}}}{\mathrm{a}_{1} \mathrm{~V}_{\mathrm{T}}}\right)}{\mathrm{a}_{1} \mathrm{~V}_{\mathrm{T}}}-\frac{\mathrm{I}_{02} \exp \left(\frac{\mathrm{V}+\mathrm{R}_{\mathrm{S}} \mathrm{I}_{\mathrm{PV}}}{\mathrm{a}_{2} \mathrm{~V}_{\mathrm{T}}}\right)}{\mathrm{a}_{2} \mathrm{~V}_{\mathrm{T}}}\right. \\
\left.-\frac{1}{\mathrm{R}_{\mathrm{P}}}\right] \dot{\mathrm{V}}_{\mathrm{PV}}(28)
\end{gathered}
$$

In order to guarantee the asymptotic stability of the system and the convergence of the errors $\mathrm{e}_{1}$ and $\mathrm{e}_{2}$ to zero, a composite Lyapunov function $\mathrm{V}_{2}$ is defined as:

$V_{2}=V_{1}+\frac{1}{2} e_{2}^{2}$

The derivative of $\mathrm{V}_{2}$ with respect to the time is:

$\dot{\mathrm{V}}_{2}=\dot{\mathrm{V}}_{1}+e_{2} \dot{\mathrm{e}}_{2}$

By using equation (24) the derivative of $\mathrm{V}_{2}$ can be expressed as:

$\dot{\mathrm{V}}_{2}=-K_{1} e_{1}^{2}+e_{2}\left[\frac{1}{\mathrm{~L}_{1}} \mathrm{~V}_{\mathrm{pv}}-\frac{1}{\mathrm{~L}_{1}}(1-\mathrm{u})\left(\mathrm{V}_{\mathrm{out}}+\mathrm{V}_{\mathrm{c} 2}\right)-\dot{\mathrm{I}}_{\mathrm{d}}-\frac{\mathrm{e}_{1}}{\mathrm{C}_{1}}\right]$

The time derivative of Lyapunov function has to be negative definite:

$\frac{1}{\mathrm{~L}_{1}} \mathrm{~V}_{\mathrm{pv}}-\frac{1}{\mathrm{~L}_{1}}(1-\mathrm{u})\left(\mathrm{V}_{\text {out }}+\mathrm{V}_{\mathrm{c} 2}\right)-\dot{\mathrm{I}}_{\mathrm{d}}-\frac{\mathrm{e}_{1}}{\mathrm{C}_{1}}=-K_{2} e_{2}$

where $\mathrm{K}_{2}$ is a positive constant

The control law, which guarantees $\mathrm{e}_{1}, \mathrm{e}_{2}$ converges asymptotically to 0 , is given by:

$\mathrm{u}=1-\left[\mathrm{V}_{\mathrm{PV}}+\mathrm{L}_{1}\left(\mathrm{~K}_{2} \mathrm{e}_{2}-\frac{\mathrm{e}_{1}}{\mathrm{C}_{1}}-\dot{\mathrm{I}}_{\mathrm{d}}\right)\right] \frac{1}{\mathrm{~V}_{\mathrm{C} 2}+\mathrm{V}_{0}}$

\section{Simulation results}

In order to study the performance of the proposed method, a simulation was carried out in Matlab software. The parameters of the simulation are illustrated in Table 3.

Table 3: Parameters of the SEPIC

\begin{tabular}{ll}
\hline Parameter & Value \\
\hline Inductor 1 $\left(\mathrm{L}_{1}\right)$ & $2.5 \mathrm{mH}$ \\
Inductor 2 $\left(\mathrm{L}_{2}\right)$ & $2.5 \mathrm{mH}$ \\
Capacitor 1 $\left(\mathrm{C}_{1}\right)$ & $4500 \mathrm{uF}$ \\
Capacitor 2 $\left(\mathrm{C}_{2}\right)$ & $79 \mu \mathrm{F}$ \\
Capacitor 3 $\left(\mathrm{C}_{3}\right)$ & $2400 \mu \mathrm{F}$ \\
Constant $(\lambda)$ & 1 \\
Constant $\left(\mathrm{K}_{1}\right)$ & $10^{4}$ \\
Constant $\left(\mathrm{K}_{2}\right)$ & $10^{4}$ \\
Load resistor $(\mathrm{R})$ & $50 \Omega$ \\
Switching frequency $(\mathrm{f})$ & $7 \mathrm{KHz}$ \\
\hline
\end{tabular}

The system being simulated into different temperature and irradiation condition as shown in Figure 6, During the first case the $[0 \mathrm{~s}, 20 \mathrm{~s}]$, the PV module is consider operating under the irradiation of the maximum power point while the temperature was raised to $318 \mathrm{~K}$ to simulate the temperature effect. In the second case $[20 \mathrm{~s}, 40 \mathrm{~s}]$, the irradiation drop smoothly from 1000 $\mathrm{W} / \mathrm{m}^{2}$ to $600 \mathrm{~W} / \mathrm{m}^{2}$ while the temperature decrease between two consecutive levels from $318 \mathrm{k}$ to $307 \mathrm{~K}$. In the last case [40s, 60s], the temperature is considered constant in $298 \mathrm{~K}$ while the irradiation increase among two successive stage to reach 1000 $\mathrm{W} / \mathrm{m}^{2}$ thus the PV module is considered operating in the maximum power point.
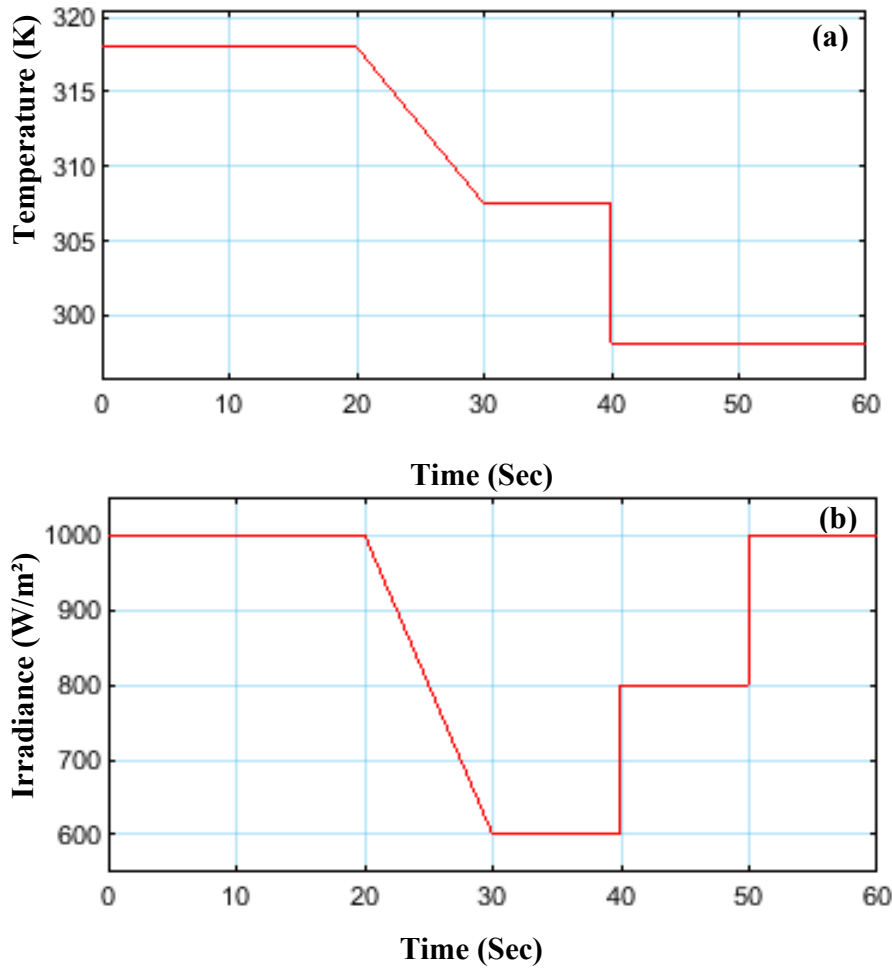

Figure 6: Temperature (a) and Irradiation (b)

Figure 7 shows that the variations in temperature and irradiation cause a slight variation in voltage and a large variation in current and power. By comparing the proposed method with the method proposed by [7] it can be seen that the proposed method bring reach the reference voltage in $25 \mathrm{~ms}$, Figure (b), with high accuracy, in contrast the proposed method in [7] reaches the desired voltage with a delay of $60 \mathrm{~ms}$ with large oscillations. In addition the obtained curves exhibit fast and good reactions when sudden variation in temperature and irradiance occurs.

Figure 8 shows the output current, voltage and power of the PV module generated at the output of the SEPIC converter using the proposed method with the result proposed by [7]. As can be seen from the figures (a), (b) and (c), the obtained curves using sliding mode controller present large oscillations and the use of the proposed method allow reducing significantly the magnitude of the fluctuation, which guarantees good performance in the maximum point tracking. 

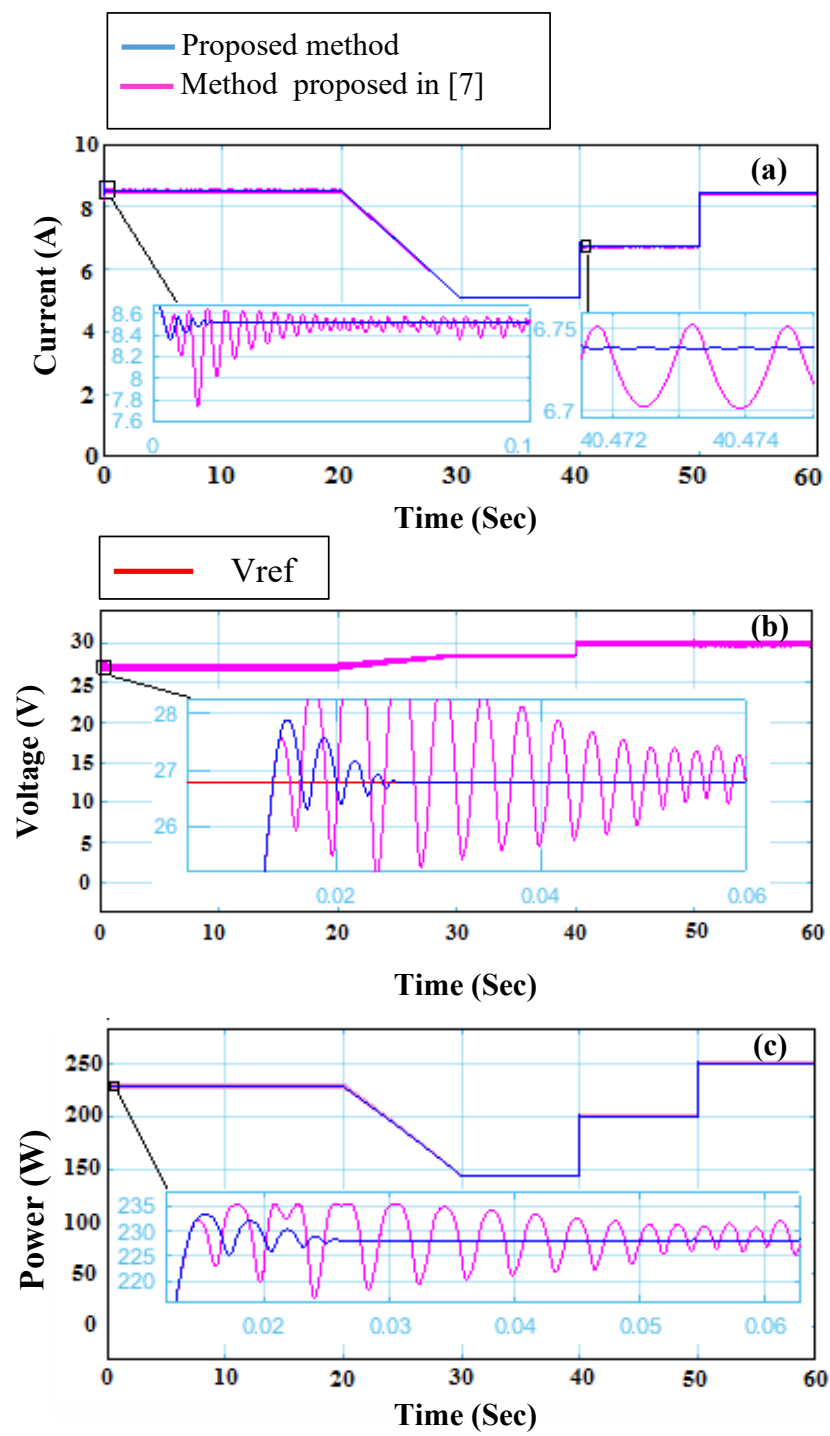

Figure 7: Photovoltaic Current (a), Voltage (b) and Power (c),
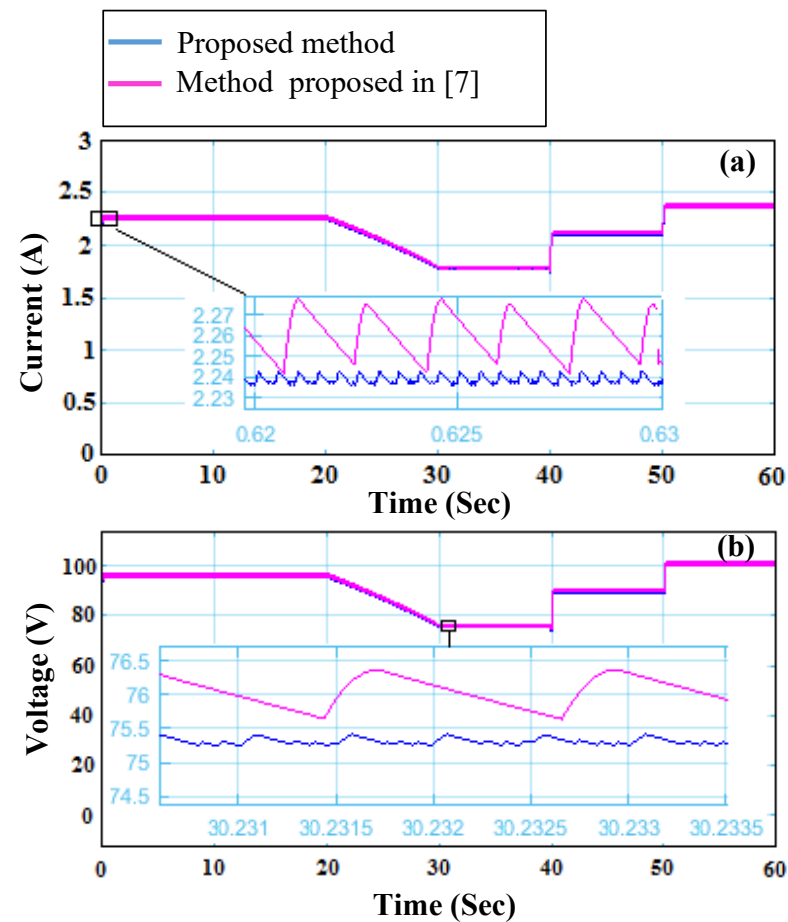

www.astesj.com

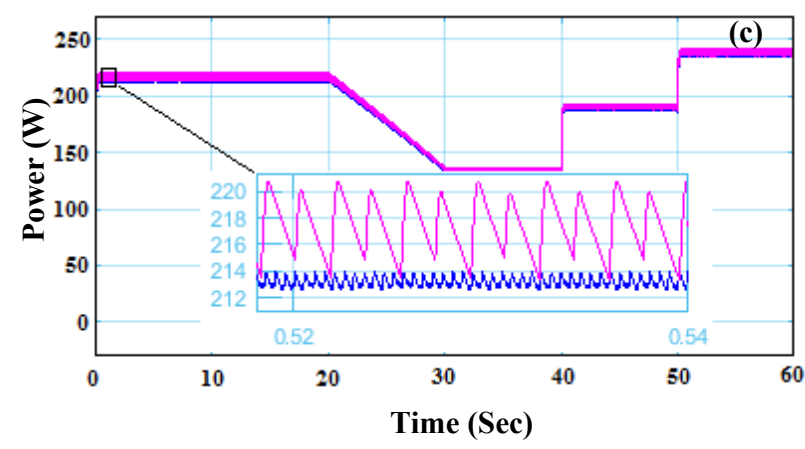

Figure 8: SEPIC output Current (a), Voltage (b) and Power (c).

\section{Conclusion}

In this paper an integral backstepping controller for maximum power point tracking is proposed. In order to increase the performance of tracking the controller was developed by combining backstepping controller and artificial neural network (ANN). The photovoltaic modelling was carried out using double diode model as the modelling using single diode degrade at low irradiance, and in order to reduce the current ripples the single ended primary inductor converter (SEPIC) has been employed. The simulation has been done in Matlab/Simulink software, the results show that the proposed method tracks the reference voltage with good accuracy and fast convergence speed, in addition the photovoltaic power reaches maximum power in less than $25 \mathrm{~ms}$. Furthermore the obtained curves show that there are no oscillations in the output voltage, current and power. Thus the proposed method presents a fast and stable reaction when the environmental conditions changes, which confirms the effectiveness and the stability of the proposed method.

\section{Conflict of Interest}

The authors declare no conflict of interest.

\section{References}

[1] T. Esram, P.L. Chapman, "Comparison of photovoltaic array maximum power point tracking techniques," IEEE Transactions on Energy Conversion, 22(2), 439-449, 2007, doi:10.1109/TEC.2006.874230.

[2] M.K. Dr S.R.Kapoor, "Comparison between IC and Fuzzy Logic MPPT Algorithm Based Solar PV System using Boost Converter," International Journal of Advanced Research in Electrical, Electronics and Instrumentation Engineering, $\quad$ 04(06), 4927-4939, 2015, doi:10.15662/ijareeie.2015.0406007.

[3] J.P. Ram, T.S. Babu, N. Rajasekar, "A comprehensive review on solar PV maximum power point tracking techniques," Renewable and Sustainable Energy Reviews, 67, 826-847, 2017, doi:10.1016/j.rser.2016.09.076.

[4] M. Al-Dhaifallah, A.M. Nassef, H. Rezk, K.S. Nisar, "Optimal parameter design of fractional order control based INC-MPPT for PV system," Solar Energy, 159(June 2017), 650-664, 2018, doi:10.1016/j.solener.2017.11.040.

[5] O. Zebraoui, M. Bouzi, "Robust sliding mode control based MPPT for a PV/Wind hybrid energy system," International Journal of Intelligent Engineering and Systems, 11(5), 290-300, 2018, doi:10.22266/IJIES2018.1031.27.

[6] O. Diouri, N. Es-Sbai, F. Errahimi, A. Gaga, C. Alaoui, "Modeling and Design of Single-Phase PV Inverter with MPPT Algorithm Applied to the Boost Converter Using Back-Stepping Control in Standalone Mode," International Journal of Photoenergy, 2019, 2019, doi:10.1155/2019/7021578. 
[7] S.A. Touil, N. Boudjerda, A. Boubakir, K. El Khamlichi Drissi, "A sliding mode control and artificial neural network based MPPT for a direct gridconnected photovoltaic source," Asian Journal of Control, 21(4), 18921905, 2019, doi:10.1002/asjc.2007.

[8] W.M. Moussa, "Modeling and Performance Evaluation of a DC/DC SEPIC Converter," Proceedings of 1995 IEEE Applied Power Electronics Conference and Exposition, 1995, 1995, doi: 10.1109/APEC.1995.469096

[9] D. Adar, G. Rahav, S. Ben-Yaakov, "A unified behavioral average model of SEPIC converters with coupled inductors," Power Processing and Electronic Specialists Conference 1997, 1997,doi: 10.1109/PESC.1997.616761

[10] E. Durán, M. Sidrach-De-Cardona, J. Galán, J.M. Andújar, “Comparative analysis of Buck-Boost converters used to obtain I-V characteristic curves of photovoltaic modules," PESC Record - IEEE Annual Power Electronics Specialists Conference, 2036-2042, 2008, doi:10.1109/PESC.2008.4592243.

[11] A.R. Kashyap, R. Ahmadi, J.W. Kimball, "Input voltage control of SEPIC for maximum power point tracking," 2013 IEEE Power and Energy Conference at Illinois, PECI 2013, 30-35, 2013, doi:10.1109/PECI.2013.6506030.

[12] R.W. Erickson, D. Maksimovic, Fundamentals of Power Electronics, 2nd Edition, 2001

[13] K. Chennoufi, M. Ferfra, M. Mokhlis, "An accurate modelling of PV Modules based on two-diode model," Renewable Energy, 2020, https://doi.org/10.1016/j.renene.2020.11.085.

[14] N. Nambiar, R.S. Palackal, K. V. Greeshma, A. Chitra, "PV fed MLI with ANN based MPPT," 4th IEEE Sponsored International Conference on Computation of Power, Energy, Information and Communication, ICCPEIC 2015, 293-300, 2015, doi:10.1109/ICCPEIC.2015.7259478.

[15] S.Z. Hassan, H. Li, T. Kamal, J. Ahmad, M.H. Riaz, M. A. Khan, "Performance of Different MPPT Control Techniques for Photovoltaic Systems" in 5th International Conference on Electrical Engineering, UET Lahore, Pakistan from Feb. 15-16th, 2018, doi: 10.1109/ICEE.2018.8566713

[16] S.Z. Hassan, H. Li, T. Kamal, L. Khan, S. Mumtaz, "Neuro-Fuzzy Wavelet Based Adaptive MPPT Algorithm for Photovoltaic Systems" Energies, 10(3), 2017, doi: 10.3390/en10030394 